\title{
OS INCENDIOS FORESTAIS E O SEU SU IMPACTO ECONÓMICO: PROPOSTA PARA UNHA AXENDA INVESTIGADORA
}

Maria L. LOUREIROa

Maria ALLÓb

a) Departamento de Fundamentos da Análise Económica. Facultad de C. Económicas. Universidad de Santiago de Compostela. Santiago de Compostela, Spain. Email: maria.loureiro@usc.es

b) Departamento de Economía. Facultad de Economía y Empresa. Universidad de A Coruña. Campus de Elviña, s/n, 15071. A Coruña. Spain. maria.allo.pazos@udc.es

\section{Resumo:}

Os incendios forestais son un dos maiores problemas ambientais aos que se está a afrontar o sur de Europa dada a virulencia que están a alcanzar nestes últimos anos. Ante esta situación, é importante levar a cabo unha valoración económica de alcance, que considere ademáis dos custos directos o impacto sufrido como consecuencia da perda dos servizos ecosistémicos forestais. Este punto é de vital importancia, posto que dita estimación axudará a reclamar unha correcta compensación para as comunidades afectadas. Tamén, á súa vez dita estimación constitúe unha información útil para a xestión e priorización de accións de defensa contra incendios. 0 obxectivo deste pequeno artigo é presentar as clasificacións máis relevantes existentes en canto aos danos dos servizos ecosistémicos perdidos, destacando as últimas metodoloxías dispoñibles e amosando a través dun caso de estudo concreto, a importancia de considerar a valoración económica deste tipo de perdas.

Palabras chave: servizos ecosistémicos, incendios forestais, dano económico

Clasificación JEL: Q51, Q53, Q54

\section{Introducción}

Os incendios forestais son un dos maiores problemas ambientais aos que se está a afrontar o sur de Europa. A Comisión Europea (2017) sinalou no seu último informe sobre este tipo de sinistros, como os montes, as terras agrícolas e os espazos naturais foron queimados con especial virulencia neste pasado ano 2017. En particular, destacan o mes de setembro, como un dos máis devastadores, dado que os incendios forestais queimaron perto de 700.000ha de terra na Unión Europea. Dentro da Península Ibérica, destacan polo seu grao de afectación a zona norte de España (Galicia en particular) e Portugal. 0 Gráfico 1 amosa a evolución dos incendios forestais en ambos países para o período 1980 -2016; así coma os datos dispoñibles para Galicia (2001-2015). Comparando os datos de ambos países, todo parece indicar que seguen unha mesma tendencia de ocorrencia.

Outro elemento a ter en conta é o peso relativo dos incendios. En Portugal, os incendios forestais do ano 2013 (dato máis recente dispoñible) representaron o 35\% do total de incendios en Europa. No caso español, a porcentaxe tamén é alta, situándose arredor dun $20 \%$ dos incendios europeos (Gráfico 2). 


\section{Gráfico 1: Número de incendios forestais.}

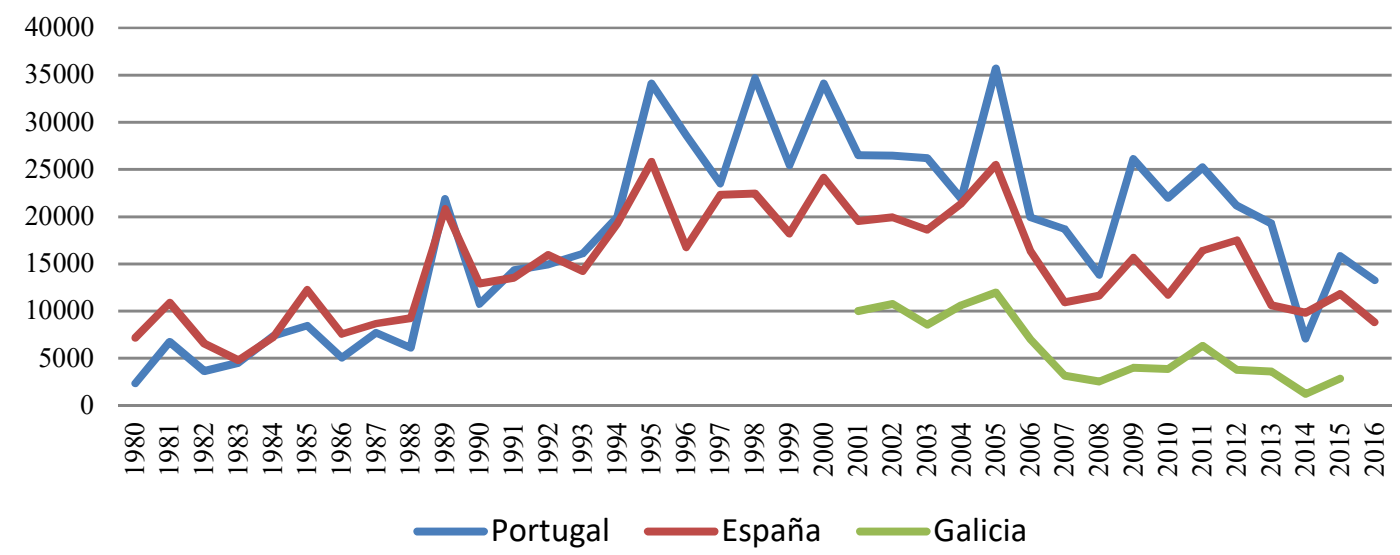

Fonte: Elaborado a partir do Sistema de Información Europeo de Incendios Forestales (SIEIF, 2017); Instituto Galego de Estatística (IGE; 2018), Ministerio de Agricultura, Pesca, Alimentación y

Gráfico 2: Porcentaxe de incendios forestais en España e Portugal sobre o total de incendios forestais en Europa

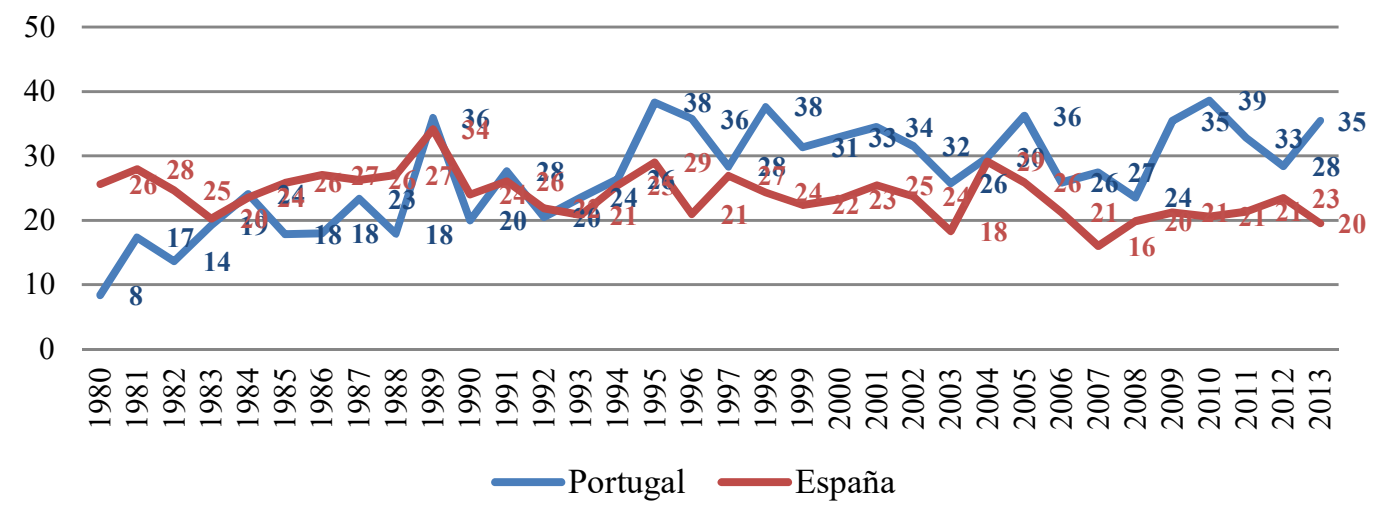

Fonte: Elaboración propia a través do Sistema de Información Europeo de Incendios Forestais, SIEIF (2017).

Ante esta situación, é importante ter en conta os danos causados por este tipo de incendios. En concreto, é fundamental considerar tanto as perdas económicas directas, coma os danos ambientais e culturais (perda dos servizos prestados polos ecosistemas, así coma perdas e danos arqueolóxicos, entre outros) ou os danos á saúde humana, dado que son elementos fundamentais cando se trata de estudar o dano total ocasionado. A avaliación dos danos causados pola perda dos servizos ecosistémicos é de vital importancia, posto que dita estimación (mais completa) axudará a reclamar unha correcta compensación para as comunidades afectadas. Tamén, á súa vez constitúen unha información útil para a xestión e priorización de accións de defensa contra incendios. 0 obxectivo deste artigo é presentar as clasificacións máis relevantes existentes en canto aos danos dos servizos ecosistémicos perdidos, destacando as últimas metodoloxías dispoñibles e amosando a través dun caso de estudo, a importancia de considerar a valoración económica deste tipo de perdas. 


\section{Clasificación dos servicios ecosistémicos a valorar}

No ano 2009 desenvolveuse a clasificación coñecida como Clasificación Internacional Común dos Servizos Ecosistémicos ("Common International Classification of Ecosystem Services", CICES). Nesta clasificación os servizos ecosistémicos identifícanse como "as contribucións" que os ecosistemas fan ao benestar humano, tendo en conta os bens e os beneficios que posteriormente as persoas obteñen deles. Tamén se recalca a idea de "o que os ecosistemas fan para a sociedade". 0 principal obxectivo foi crear unha clasificación que relacionase os usos ou propósitos que os individuos teñen dos servizos ecosistémicos, sobre as características ou comportamentos dos servizos do ecosistema que o apoian. Existen outras clasificacións como a proposta polo Millennium Ecosystem Assessment (MEA) ou The Economics of Ecosystem and Biodiversity (TEEB), onde os servizos dos ecosistemas se clasifican en diferentes categorías: servizos de provisión, servizos de regulación, servizos hábitat ou de apoio e servizos culturais. Sen embargo, o CICES é a clasificación recomendada por Eurostat a día de hoxe.

Na última versión da clasificación CICES (CICES, V5.1) identifícase o uso final que as persoas fan dos diferentes servizos ecosistémicos e as características particulares dos mesmos. En concreto, no marco CICES existen grupos de servizos ecosistémicos e dentro de cada grupo atopamos diferentes divisións que representan unha estrutura xerárquica deseñada para a contabilidade dos servizos dos que nos provén os ecosistemas e que está dacordo coa División de Estatística das Nacións Unidas (UNSD). Segundo a clasificación dos CICES, as principais categorías de servizos ecosistémicos que podemos sinalar son as tres seguintes:

Servizos de provisión: "os produtos dos sistemas vivos e abióticos (nutricionais, non nutricionais, materiais e enerxía)".

Servizos de regulación e mantemento: "todas as formas en que os organismos vivos poden mediar ou moderar o medio ambiente que afecta a saúde humana, a seguridade ou o confort, xunto cos seus equivalentes abióticos".

Servizos culturais: "todos os produtos non-materiais e, xeralmente, non rivais e non consumibles dos ecosistemas (bióticos e abióticos) que afectan aos estados físicos e mentais das persoas". Representan ambientes ambientais, lugares, lugares que inflúen nos estados mentais dos individuos.

Haynes-Young e Potschin (2018) elaboraron unha guía sobre a aplicación CICES na que destacan que o marco conceptual da clasificación pode especificarse en forma dun modelo en cascada, tomando como exemplo o modelo xa proposto por Potschin e Haynes-Young (2016); que se representa na Figura 1. 0 obxectivo é por tanto clasificar os servizos dos ecosistemas; é dicir, realizar unha categorización das contribucións que os ecosistemas proporcionan ao benestar humán.

Sen embargo, é importante ter en conta que parte destes servizos ecosistémicos non teñen un valor nin un prezo de mercado asociado. Por tanto, tamén é necesario aclarar as metodoloxías de valoración axeitadas, e tamén reflexionar sobre aquelas menos recomendables.

A nivel español unha das primeiras aportacións que nos guían en canto a valoración das perdas forestais é o "Manual de Valoración de Pérdidas y Estimación del Impacto Ambiental por Incendios Forestales" (Ministerio de Medio Ambiente, 1996). Tamén existen contribucións posteriores do Ministerio de Agricultura e Alimentación, Pesca e Medio 
Ambiente, tales como o proxecto VANE (Valoración de Activos Ambientais en España), ademais do proxecto Avaliación dos Ecosistemas do Milenio en España (EME).

Figura 1: 0 modelo de cascada

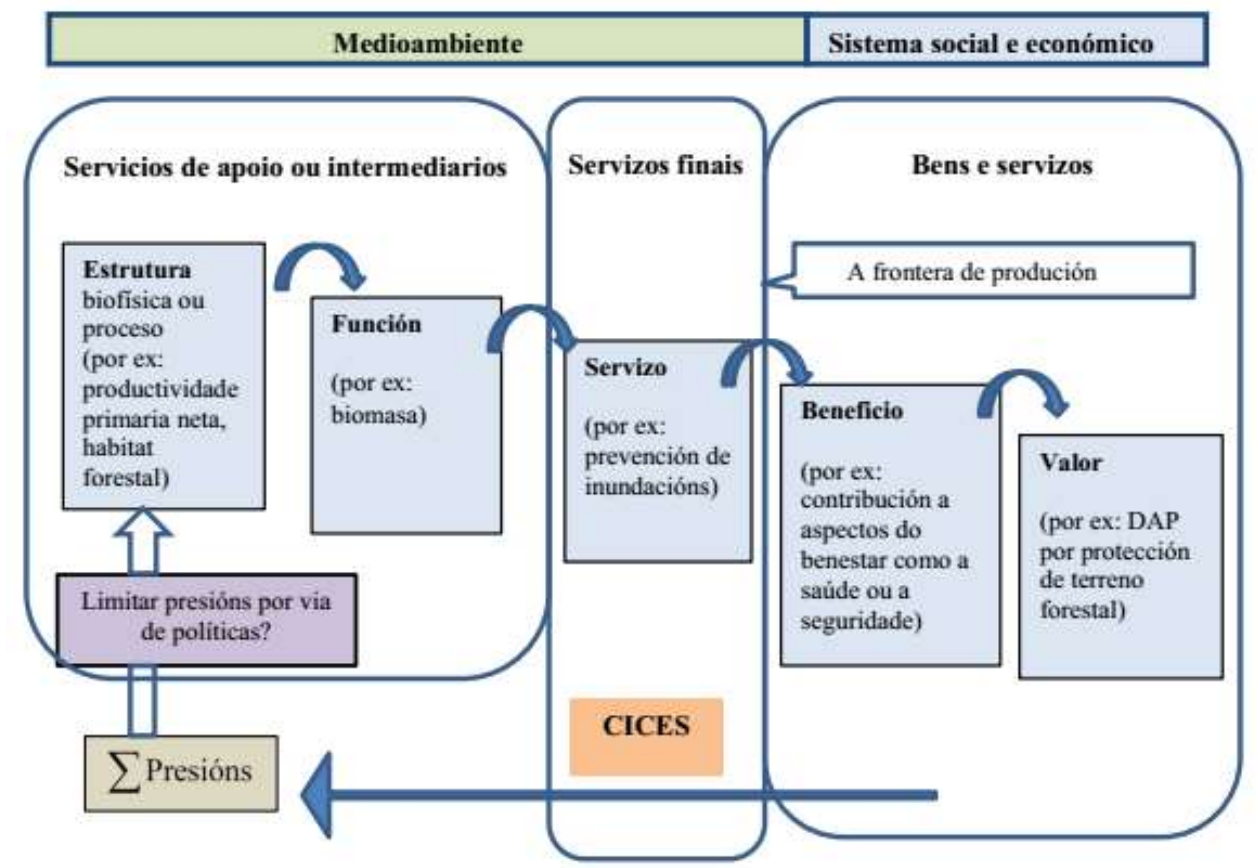

Fonte: Elaborado a partir de Haynes-Young e Potschin (2018)

A nivel internacional é relevante considerar a "Norma Marco Central del Sistema de Contabilidad Ambiental y Económica " (SCAE, acrónimo en inglés SEEA), creada polas Nacións Unidas e o Banco Mundial, para integrar a contabilidade do capital natural dentro das estadísticas producidas polos distintos paises. Esta norma é o resultado de numerosos grupos de traballo e versións diferentes, o último do ano 2012, e que consta doutros documentos como o FDES (Framework for Development of Environmental Statistics, 2013), os sistemas de contas nacionais e os manuais de Estatísticas e contabilidade agrícola e forestal publicadas por institucións internacionais. A SEEA describe as interaccións entre economía e medio ambiente, así como accións e cambios nos activos ambientais. Polo tanto, calquera estudo de valoración dos servizos dos ecosistemas debería seguir a clasificación CICES e os principios do SEEA, ademáis das recomendacións do Eurostat.

Esta visión máis holística dos danos, contrasta ata o momento cas estimacións someras e parciais feitas para moitos casos. Tomando como exemplo os incendios forestais acaecidos en Galicia no ano 2017, a maioría das estimacións proporcionadas presentan só os danos directos aos propietarios da madeira, menosprezando unha serie de gastos adicionais e custos á sociedade. Dita limitación dos danos pode, por tanto, sesgar o debate público en torno a esta problemática. Por exemplo, o dano económico estimado pola Asociación Forestal de Galicia a consecuencia dos incendios forestais que tiveron lugar durante os días 15 e 16 de outubro no sur da provincia de Pontevedra está en torno aos $29 €$ millóns (Faro de Vigo, 2017); mentras que outras informacións recalcan que Xunta de Galicia dispuxo arredor de $22 €$ millóns co fin de paliar os danos ocasionados polos incendios que tiveron 
lugar nesa fin de semana (La Voz de Galicia, 2018). Ainda que estas estimacións poden ser completamente certas en canto ao dano material ocasionado a particulares, se levamos a cabo unha estimación a curto prazo e conservadora, presentando estimacións que seguen a clasificación CICES, os devanditos danos multiplicanse de xeito significativo. As vindeiras seccións ilustran o dano social ocasionado polos incendios forestais da provincia de Pontevedra en Outubro 2017, debido a reducción dos servizos ecosistémicos de provisión, regulación (vencellados ao servizo de sumidoiro de CO2) e servizos culturais.

\section{Descrición do caso de estudo}

Neste caso de estudo trata de valorarse o impacto económico sufrido a consecuencia da vaga de incendios que asolou á provincia de Pontevedra nos días 13 a 16 de outubro 2017. O Mapa 1 achega unha visión xeral do día 15 de outubro (o día de maior incidencia).

Mapa 1: Incendios forestais en Pontevedra, 15 de Outubro 2017.
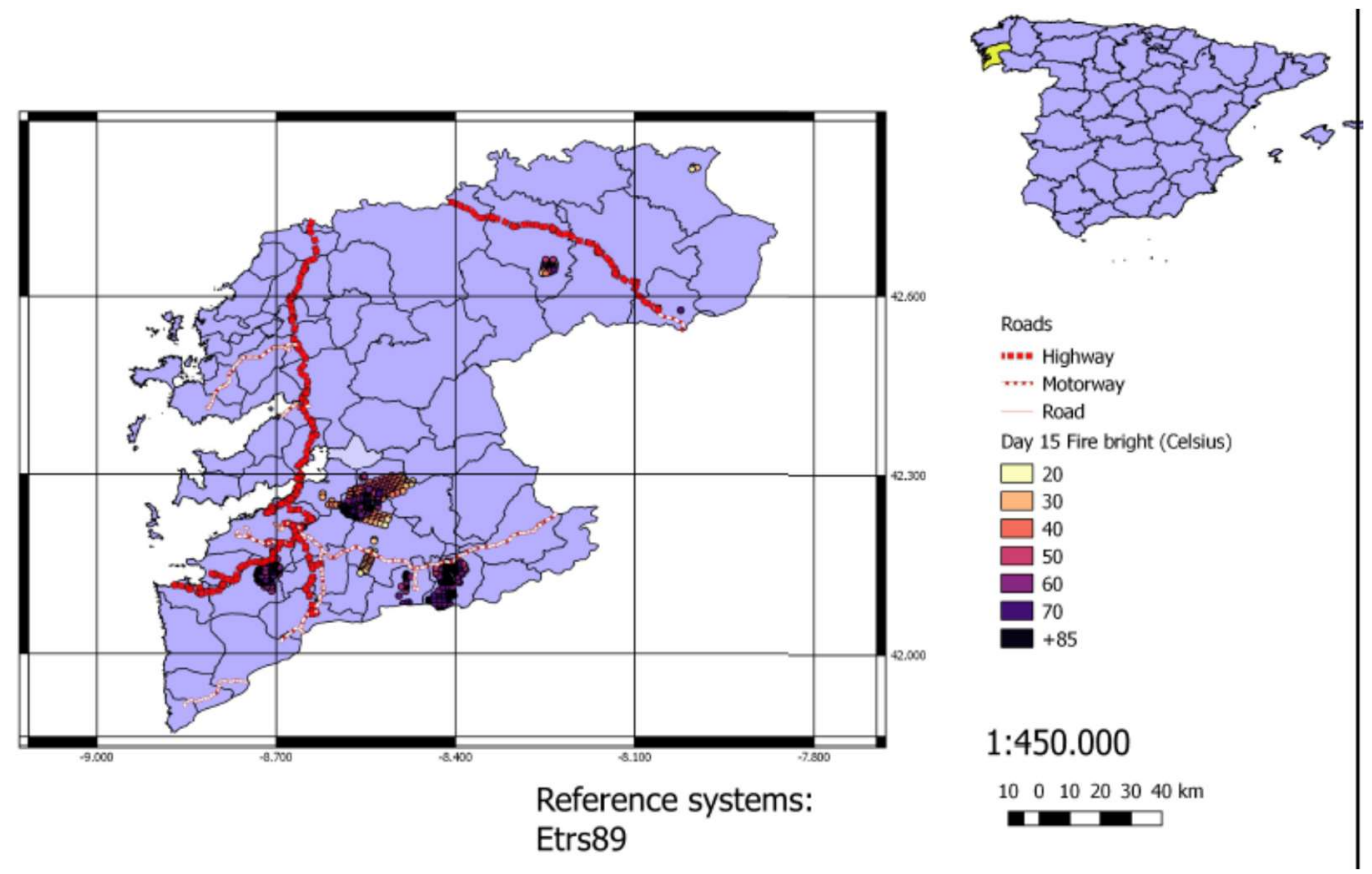

Fonte: Elaboración propia a partir de datos da NASA (2017a, 2017b).

Os datos utilizados neste artigo foron recollidos dende imaxes do satélite de MODIS e VIRRS (Visible Infrared Imaging Radiometer Suite) (NASA 2017a, NASA 2017b). A detección de incendios en MODIS faise do seguinte modo. Os satélites toman unha instantánea da Terra e cada punto de detección de incendios activos representa o centro dun píxel de $1 \mathrm{~km}$ que pode conter un ou máis incendios ou outras anomalías térmicas (por exemplo, volcáns). A localización é o punto central do píxel e o tamaño real pode variar segundo o escaneo. É certo, que o lume tende a ter menos de $1 \mathrm{~km}$ de tamaño nos estadíos iniciais, polo que non é posible determinar o tamaño exacto dos pequenos incendios. 
Ademais destes datos satelitais, tamén se tivo en conta a información do Inventario Forestal Nacional para clasificar as principais especies afectadas. Segundo datos oficiais, estímase que preto de 43.541ha foron afectadas en Pontevedra durante eses días e arredor dun 90\% queimáronse durante o 15 de outubro, xerando unha situación de gran urxencia. En España, durante o ano 2017, rexistráronse un total de 56 grandes incendios forestais (GIF), dos cales 9 tiveron lugar nesta mesma provincia, Pontevedra (Ministerio de Agricultura, Pesca y Alimentación (MAPAMA) 2018). A rápida evolución e propagación destes incendios móstrase nos mapas 2 a 5 como un exemplo do avance do lume durante o día máis crítico (15 de outubro). Os incendios comezaron no concello de Pazos de Borbén, estendéndose en horas posteriores a Salvaterra do Miño, Gondomar e As Neves, concellos que tamén quedaron significativamente afectados.

Cómpre salientar que durante o primeiro día só se viron afectados dous municipios (Silleda e Rodeiro); mentres que o segundo día (o día con menor incidencia) só o concello, Dozón foi afectado. Pola contra, durante o terceiro día, o día máis grave, preto de 13 concellos sufriron incendios forestais. En concreto, máis do 75,54\% da área queimada total concentrouse en catro deles (Pazos de Borbén, Gondomar, Ponteareas e As Neves). Xa no último día, os municipios de Agolada, Ponteareas e Salceda de Caselas rexistraron tamén incendios forestais.

Mapa 2: Incendios forestais en Pontevedra, 15 de outubro de 2017 (primeira fase) (hora: 01:34)

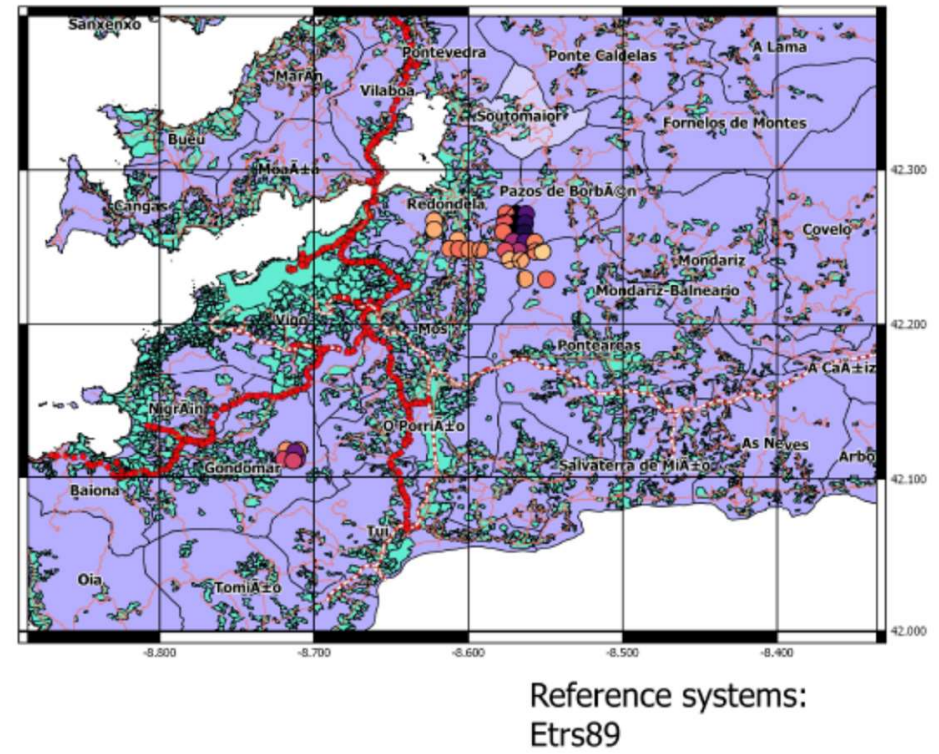

Fonte: elaboración propia a partir de datos de NASA (2017a, 2017b).

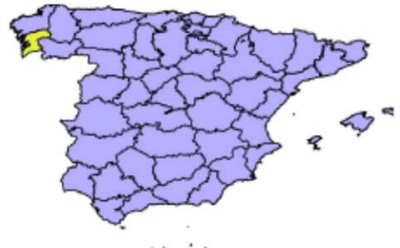

$\square$ Population centre

Roads

w... Highway

.... Motorway

- Road

Day 15 Fire bright (Celsius)

$\square 20$

$\square 30$

$\square 40$

50

70

$1: 175.000$

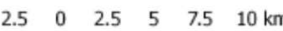

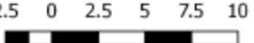

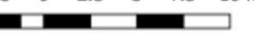


Mapa 3: Incendios forestais en Pontevedra, 15 de outubro de 2017 ( $2^{\mathrm{a}}$ fase) (hora: 03:15)

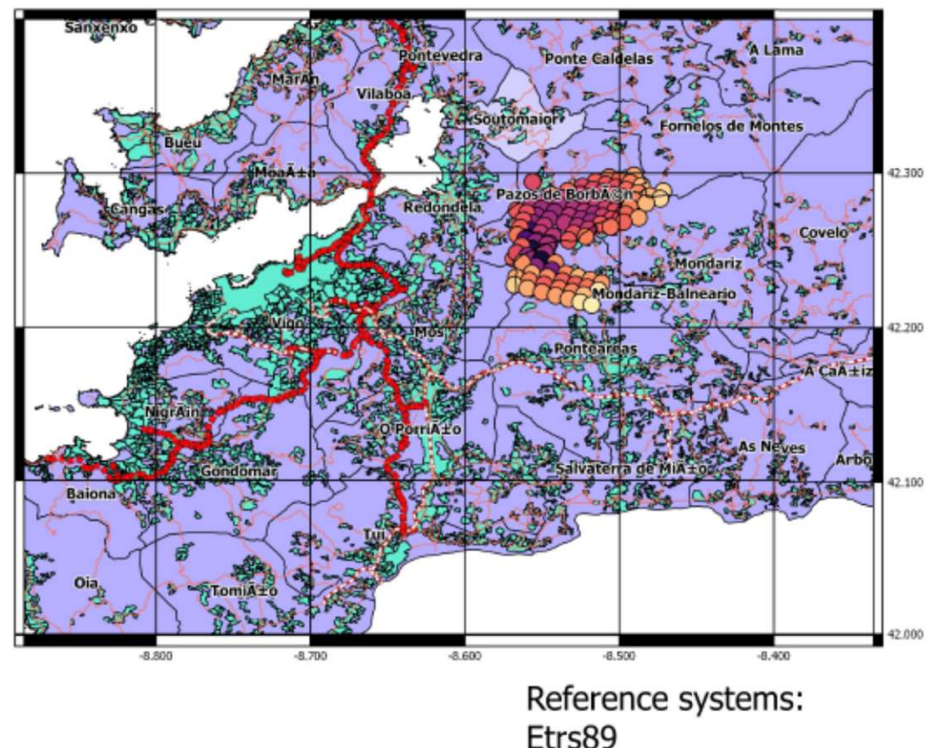

Etrs89

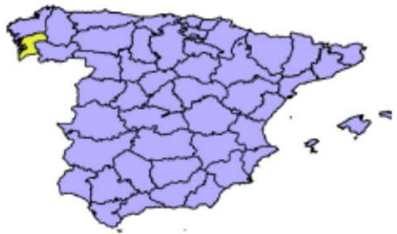

$\square$ Population centre

Roads

..... Highway

.... Motorway

Road

Day 15 Fire bright (Celsius)

$\square 20$

$\square 30$

$\square 30$

50

60
$\square$

$1: 175.000$

Fonte: elaboración propia a partir de datos de NASA (2017a, 2017b).

Mapa 4: Incendios forestais en Pontevedra, 15 de outubro de 2017 (3 $3^{\text {a }}$ fase) (hora: 12:58)

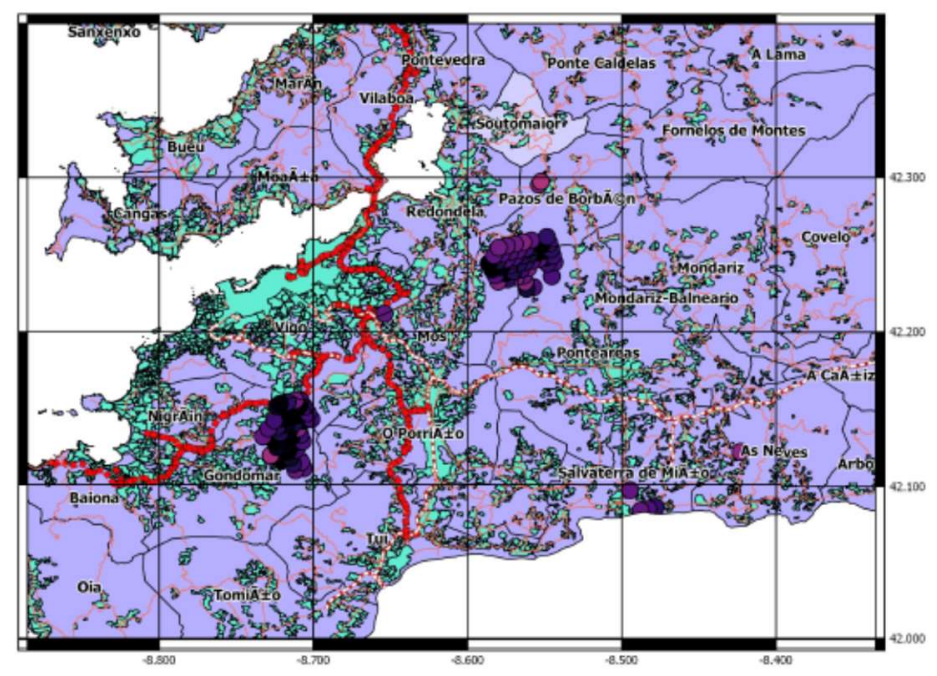

Reference systems: Etrs89

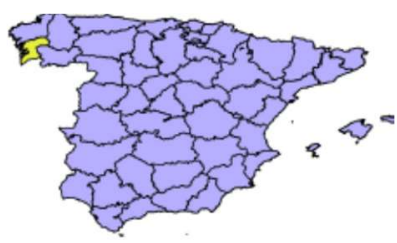

$\square$ Population centre

Raads

n... Highway

-... Motorway

Day 15 Fire bright (Celsius)

$\square 20$

$\square 30$

$\square 0$

$\square 0$

$1: 175.000$

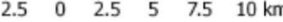

Fonte: elaboración propia a partir de datos de NASA (2017a, 2017b). 
Mapa 5: Incendios forestais en Pontevedra, 15 de outubro de 2017 (4⿳⺈冂a fase) (hora: 14:39)
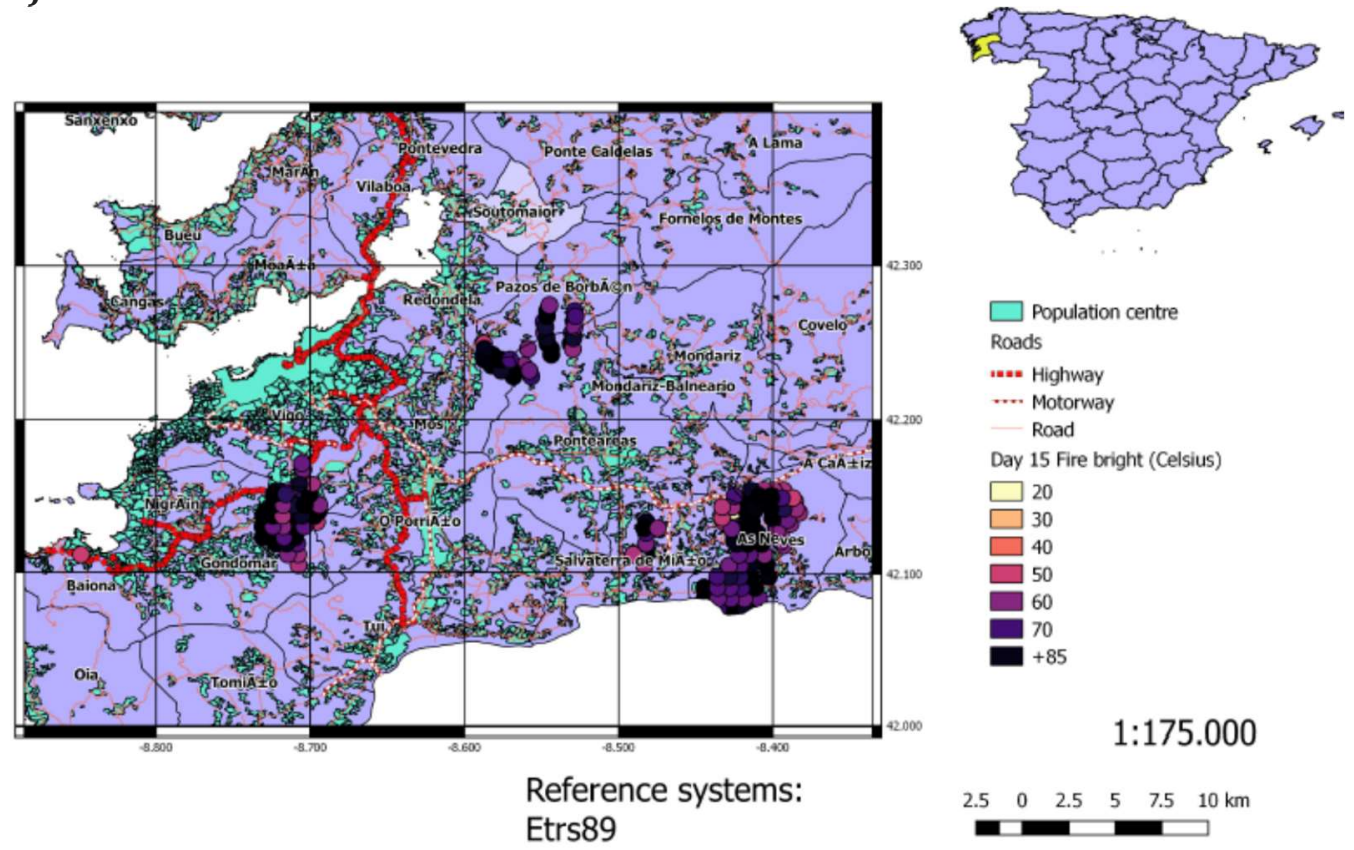

.... Motorway

$$
\text { Road }
$$

Day 15 Fire bright (Celsius)

$\square 20$

$\square 30$

$\square 50$

60
70

Etrs89

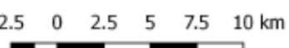

Fonte: elaboración propia a partir de datos de NASA (2017a, 2017b).

Unha característica destes últimos incendios é que ao redor do 9,7\% da área total queimada afectou a núcleos urbanos (4.218ha), destacando así a gravidade destes episodios na que un número significativo de cidadáns chegaron a estar en situacións de risco. A continuación, e na medida do posible, presentamos un resumo das perdas máis importantes, clasificadas segundo CICES.

\section{Estimación do impacto económico}

\section{a. Perdas económicas no sector madeireiro}

Para aproximarnos aos danos económicos da madeira queimada en 2017 é preciso ter información sobre o tipo de especie que ardeu, o seu tamaño (idade), e a severidade do lume, así coma as respectivas perdas en prezo da madeira queimada debido ao incendio. Estas perdas de prezos poden ascender ao valor total da mesma ou só ser unha proporción, dependendo da gravidade do incendio. Cómpre salientar que cando os recentes inventarios forestais non están dispoñibles, só se pode achegar unha aproximación destes danos.

A través da análise dos datos dispoñibles, atopouse que as especies máis afectadas foron o Eucalyptus Globulus, seguido polo Pinus Pinaster, o Quercus Robus eo Pinus Radiata. En total, na provincia de Pontevedra, queimáronse 24.959ha de monte produtivo nos catro días de incendios do mes de outubro de 2017. Preto do 78,42\% desta área estaba ocupada por tres especies principais, segundo os datos de satélite proporcionados por Picos (2018a) (Táboa 1). 
Co obxectivo de estimar as perdas económicas, calculouse un prezo residual medio como resultado entre a diferenza do prezo de serrado proporcionado por Picos (2018b) menos o prezo da poxa destes montes queimados como consecuencia dos incendios forestais (Xunta de Galicia 2018 ). A Táboa 1 mostra os danos estimados producidos en Pontevedra en 2017 no sector madeireiro. Especificamente, o dano económico estímase ao redor dos 56.826.532€.

Táboa 1: Perdas económicas no sector madeireiro

\begin{tabular}{|c|c|c|c|c|c|c|}
\hline & $\begin{array}{c}\text { Severidade do } \\
\text { lume }\end{array}$ & $\begin{array}{l}\text { Ha } \\
\text { quei } \\
\text { Ma } \\
\text { das }\end{array}$ & $\begin{array}{c}\text { Volume } \\
\text { estimado medio } \\
\text { (m³/hectárea) }\end{array}$ & $\begin{array}{c}\text { Total } \\
\text { do } \\
\text { volum } \\
\text { en } \\
\text { estima } \\
\text { do } \\
\left(\mathrm{m}^{3}\right) \\
\end{array}$ & $\begin{array}{c}\text { Prezo } \\
\text { resid } \\
\text { ual } \\
\left(€ / \mathrm{m}^{3}\right. \\
)\end{array}$ & $\begin{array}{c}\text { Perda } \\
\text { estimad } \\
\text { a }(€)\end{array}$ \\
\hline & 1 & $\begin{array}{c}13.28 \\
5\end{array}$ & 72.63 & $\begin{array}{c}964.89 \\
0\end{array}$ & 16.65 & $\begin{array}{c}16.065 .4 \\
11\end{array}$ \\
\hline \multirow{6}{*}{$\begin{array}{c}\text { Pinus } \\
\text { pinaste } \\
\mathbf{r}\end{array}$} & 2 & 25 & 72.63 & 1.816 & 16.65 & 30.232 \\
\hline & 3 & 174 & 72.63 & 12.638 & 16.65 & 210.416 \\
\hline & 4 & 348 & 72.63 & 25.275 & 16.65 & 420.833 \\
\hline & 5 & 299 & 72.63 & 21.716 & 16.65 & 361.578 \\
\hline & Total & $\begin{array}{c}14.13 \\
1 \\
\end{array}$ & & & & $\begin{array}{c}17.088 . \\
470\end{array}$ \\
\hline & 1 & 1.131 & 99.59 & $\begin{array}{c}112.63 \\
6 \\
\end{array}$ & 10.8 & $\begin{array}{c}1.216 .47 \\
2 \\
\end{array}$ \\
\hline \multirow{6}{*}{$\begin{array}{l}\text { Pinus } \\
\text { radiata }\end{array}$} & 2 & 1 & 99.59 & 100 & 10.8 & 1.076 \\
\hline & 3 & 4.4 & 99.59 & 438 & 10.8 & 4.733 \\
\hline & 4 & 13 & 99.59 & 1.295 & 10.8 & 13.982 \\
\hline & 5 & 14 & 99.59 & 1.394 & 10.8 & 15.058 \\
\hline & Total & $\begin{array}{c}1.163 . \\
4\end{array}$ & & & & $\begin{array}{c}1.251 .3 \\
20 \\
\end{array}$ \\
\hline & 1 & 7.459 & 223.66 & $\begin{array}{c}1.668 .2 \\
80 \\
\end{array}$ & 20.5 & $\begin{array}{c}34.199 .7 \\
39 \\
\end{array}$ \\
\hline \multirow{5}{*}{$\begin{array}{c}\text { Eucalyp } \\
\text { tus } \\
\text { globulu } \\
\text { s }\end{array}$} & 2 & 44 & 223.66 & 9.841 & 20.5 & 201.741 \\
\hline & 3 & 381 & 223.66 & 85.214 & 20.5 & $\begin{array}{c}1.746 .89 \\
6 \\
\end{array}$ \\
\hline & 4 & 333 & 223.66 & 74.479 & 20.5 & $\begin{array}{c}1.526 .81 \\
5 \\
\end{array}$ \\
\hline & 5 & 177 & 223.66 & 39.588 & 20.5 & 811.550 \\
\hline & Total & 8.394 & & & & $\begin{array}{c}38.486 . \\
742 \\
\end{array}$ \\
\hline
\end{tabular}

Fonte: elaboración propia a partir de datos obtidos a través da comunicación persoal con Picos (2018b, 2018a) * Non se consideraron perdas por Quercus Robur debido á falta de prezos da poxa.

É importante apreciar que esta é unha estimación conservadora dado que unicamente se están a considerar as perdas económicas como consecuencia da queima das especies comerciais e, polo tanto, o dano económico das especies non comerciais non está computado pola falta de datos. 


\section{b. Danos relacionadas coa perda de sumidoiro de carbono}

En liña con Barrio et al. (2007), estímanse as perdas relacionadas coa asimilación de carbono. Preto de 27.230 ha de área forestal boscosa resultaron queimadas, o que implica unha perda significativa de retención de carbono por biomasa viva. Seguindo a Barrio et al. (2007), considerouse a estimación previa levada a cabo por Dans e Molina (2005), é dicir, asumiuse que a biomasa viva asimila uns $3,17 \mathrm{Mg} / \mathrm{hectárea/ano} \mathrm{no} \mathrm{caso} \mathrm{das} \mathrm{frondosas} \mathrm{e}$ coníferas galegas. Así, a perda de secuestro de carbono considerando só un ano de perdas é de aproximadamente 316.505 toneladas de $\mathrm{CO} 2$.

Para calcular os danos económicos ocasionados pola perda de captación de carbono, utilízase o custo social do carbono para estimar o dano actual que proprociona á sociededa non ter ditos sumidoiros de carbono.

O custo social do carbono representa o dano actual en termos económicos causado pola emisión dunha tonelada de CO2. Segundo a Axencia de Protección Ambiental dos Estados Unidos (2016) para o 2015, e utilizando unha taxa de desconto do 3\%, o custo social medio do carbono estímase en 37 /tonelada, o que medido en $€$ do 2017 equivale a 33,22€.

Isto significa que a perda por captación de carbono nun ano concreto é de 10.514.296€. Esta é unha estimación conservadora debido ao feito de que a biomasa afectada non se recupera unicamente nun ano, e para restaurar a capacidade de secuestro, de feito, dependendo da idade das árbores afectadas e da biomasa viva, necesitaranse turnos ao redor de 15 ou máis anos, dependendo da especie arborea fundamentalmente.

\section{c. Efectos económicos causados polas emisións}

Co fin de aproximar as pérdidas económicas ocasionadas polas emisións dos incendios forestais, seguiuse a metodoloxía empregada por Valero et al. (2007). Así, a seguinte ecuación proporciona as emisións estimadas de CO2:

$$
L_{\text {fire }}=A^{*} M F^{*} C_{f} * G_{e f} * 10^{-3}
$$

Onde $L$ é a cantidade de emisión de gases ( $\mathrm{Mg} / \mathrm{CO} 2)$; A é a área queimada (ha); $M F$ é a masa de combustible dispoñible para a combustión (tonelada de substancia seca por hectárea); $C_{f}$ é o factor de combustión e $G_{e f}$ é o factor de emisión (g/kg de sustancia quente seca). Os datos de $M F, C_{f}, G_{e f}$ proveñen do estudo realizado por Valero et al. (2007). 
Táboa 2: Estimación das emisións de C02 polos incendios forestais.

\begin{tabular}{|lccccc|}
\hline & $\begin{array}{c}\mathbf{A} \\
\text { (hectárea) }\end{array}$ & $\begin{array}{c}\text { MF } \\
\text { (Tonelada } \\
\text { /hectárea) }\end{array}$ & $\mathbf{C}_{\mathbf{f}}$ & $\mathbf{G}_{\text {Gef }} \mathbf{g} / \mathrm{kg}$ ) & $\mathbf{L}_{\text {fire }}$ \\
\hline Eucalyptus globulus & 11.019 & 118,98 & 0,45 & 1,569 & 925.660 \\
\hline Pinus pinaster & 11.629 & 93,87 & 0,45 & 1,569 & 770.734 \\
\hline Pinus radiata & 831 & 93,87 & 0,45 & 1,569 & 55.076 \\
\hline Non se trata & 18.582 & 22,25 & 0,64 & 1,569 & 415.169 \\
\hline Total & & & & 2.166 .640 \\
\hline
\end{tabular}

Fonte: elaborado por Valero et al. (2007) e Barrio et al. (2007).

Segundo a Táboa 2, ao redor de 2.166.640 toneladas de CO2 foron emitidas á atmosfera debido a estes incendios producidos en Pontevedra en outubro de 2017. Para obter unha estimación dos custos económicos destas emisións, usouse de novo o custo social do carbono para monetarizar o valor do dano causado por cada tonelada de $\mathrm{CO} 2$ (33,22 $€ /$ tonelada C02). Polo tanto, as consecuencias das emisións de CO2 dos incendios forestais poden estimarse en $71.975 .780 €$.

\section{d. Perdas culturais}

Para monetarizar as perdas ambientais causadas por incendios relacionados con fins culturais, usos recreativos e apego emocional, aplícase a metodoloxía de transferencia de beneficios. Esta é unha técnica útil que permite transferir o valor económico dun ben público, neste caso os usos recreativos do bosque, desde un lugar de estudo ata un sitio concreto de interés (Mavsar, 2010). Os autores afirman que a transferencia de beneficios "é un proceso onde as estimacións de valores existentes transfírense a unha nova aplicación para apoiar a toma de decisións". Para realizar esta análise, é necesario seleccionar valoracións previas de estudos similares para aplicalos á nova situación de valoración, co fin de reducir o erro de transferencia (Richardson et al., 2015).

Enfocándose na literatura forestal galega, Barrio e Loureiro (2007) realizaron un estudo para avaliar a disposición a pagar (DAP) dos fogares galegos para levar a cabo unha política de prevención que permita evitar episodios como os incendios rexistrados en 2006. Os beneficios do programa de prevención proposto incluían os valores culturais e recreativos. Este estudo foi seleccionado dado que nos proporcionou a información máis comparable para o caso de Pontevedra.

En concreto, os autores estimaron que a DAP media dos fogares galegos era de aproximadamente $39,84 €$. Así, co fin de ter unha aproximación da DAP para evitar un episodio como os incendios forestais de outubro de 2017, actualizouse a estimación previa a prezos de 2017, atopando que cada fogar galego estaría disposto a pagar arredor de $45,58 €$ para evitar un episodio deste tipo. Polo tanto, aplicando esta estimación ao número de fogares que viven na provincia de Pontevedra (uns 364.100 segundo o Instituto Galego de Estatística (IGE) (2018)), estimase que a perda económica total no referente a valores de uso pasivo ascende a $16.595 .678 €$. 


\section{Conclusións}

En resumo, a clasificación dos danos e a súa consideración son elementos chave para a valoración do impacto económico ocasionado. Cabe resaltar tamén que os resultados aquí presentados son preliminares en tanto en canto un número de servizos ecosistémicos significativos non foron analizados. Por outra banda, é imperativo recoñecer que a falta de datos obrigou a utilización de determinados supostos. Estas eivas e outras esperan ser corrixidas en estimacións futuras.

Sen embargo, e a vista dos danos estimados, todo parece indicar que os grandes incendios do Outubro 2017 tiveron un impacto significativo na economía local. En concreto, a estimación a curto prazo, conservadora e parcial presentada neste artigo ascende a un total de 155,89€ millóns de perda económica; o cal contrasta en magnitude con outras estimacións previas. Por tanto, queda reflexada a importancia de valorar a perda dos servicios ecosistémicos co fin de reflexar a pérdida económica total.

A futura axenda de investigación que está pendente espera poder afondar neste ámbito de tanta relevancia para Galicia. Dada tamén a falta de datos oficiais actualizados parece necesario botar man de datos satelitais que poidan ser estudados a través de ferramentas máis precisas de teledetección, que nos permitan delimitar, e identificar as áreas queimadas. A súa vez, o acceso a outras fontes de big data en acceso aberto poderán axudarnos de forma experimental a aproximarnos a novas fontes de información que poden complementar as estatísticas oficiais. Con esta mellora e outras, espérase poder achegarnos ao impacto real ocasionado por estes episodios devastadores, co fin de dispoñer de información fiable a suministrar aos tomadores de decisións; e poder, por tanto, enriquecer o debate dende un punto de vista económico.

\section{Referencias}

Axencia de Protección Ambiental dos Estados Unidos (2016) EPA Fact Sheet. Social cost of carbon.

Barrio M, Loureiro ML (2007) Valoración de los daños económicos y ambientales ocasionados por los incendios forestales de Galicia en el año 2006. DEA. Universidade de Santiago de Compostela.

Barrio, M., Loureiro, M., Chas, M.L. (2007) Aproximación a las pérdidas económicas ocasionadas a corto plazo por los incendios forestales en Galicia en 2006. Economía Agraria y Recursos Naturales, 7(14), 45-64.

Base de datos Portugal Contemporaneo (PORDATA). Estatisticas incendios florestais. Dispoñible en: https://www.pordata.pt/Home

Common International Classification of Ecosystem Services (CICES). Available at: https://cices.eu/

Comisión Europea. (2017) Forest Fires in Europe, Middle East and North Africa 2016. Disponible online

en: 
http://effis.jrc.ec.europa.eu/media/cms page media/40/Forest fires in Europe Middle e ast and North Africa 2016 final pdf JZU7HeL.pdf.

Faro de Vigo (2017). El impacto económico de la oleada de incendios en Galicia, casi 29 millones de euros. Dispoñible online: http://www.farodevigo.es/galicia/2017/12/13/impacto-economico-oleada-incendiosgalicia/1803081.html. Último acceso online: 16/05/2018.

Framework for the Development of Environment Statistics (FDES) (2013) https://unstats.un.org/unsd/envstats/fdes.cshtml.

Haynes-Young and Potschin (2018) Common International Classification of Ecosystem Services (CICES) V5.1 Guidance on the Application of the Revised Structure. Available online at: https://seea.un.org/sites/seea.un.org/files/lg23 cices v5.1 final revised guidance 0310-2017.pdf

Instituto Galego de Estatística (IGE) (2018) Estadísticas sobre incendios forestais. Available online

https://www.ige.eu/igebdt/selector.jsp?COD=3726\&paxina=001\&c=0101001002

Instituto Galego de Estatística (IGE) (2018) Enquisa estrutural a fogares. http://www.ige.eu/web/mostrar_actividade_estatistica.jsp?idioma=gl\&codigo=0205002. Accessed 07/20/2018.

La Voz de Galicia (2018). Las ayudas de la Xunta por los incendios de octubre ascienden a 22 millones. Dispoñible online:

https://www.lavozdegalicia.es/noticia/santiago/2018/02/01/ayudas-xunta-incendiosoctubre-ascienden-22-millones/00031517493014156125899.htm. Último acceso:

$16 / 05 / 2018$.

Mavsar R (2010) Benefit (value) transfer method. http://www.efimed.efi.int/files/attachments/efimed/agora/tn workshop/e4. benefit tra nsfer.pdf

Millenium $\quad$ Ecosystem $\quad$ Assessment $\quad$ (MEA) https://www.millenniumassessment.org/en/index.html

Ministerio de Medio Ambiente. (1996) Manual de Valoración de Pérdidas y Estimación del Impacto Ambiental por Incendios Forestales. Dispoñible online: http://www.mapama.gob.es/es/desarrollo-rural/temas/politicaforestal/manual valoracion tcm30-278886.pdf

Ministerio de Agricultura e Alimentación, Pesca e Medio Ambiente (MAPAMA) Valoración de los activos naturales en España (VANE). https://www.mapama.gob.es/es/biodiversidad/temas/conservacion-de-labiodiversidad/valoracion-y-aspectos-economicos-de-labiodiversidad/cb vae valoracion activos naturales.aspx

Ministerio de Agricultura e Alimentación, Pesca e Medio Ambiente (MAPAMA) Evaluación de los ecosistemas del milenio en España (EME). 
https://www.mapama.gob.es/es/biodiversidad/temas/conservacion-de-la-

biodiversidad/valoracion-y-aspectos-economicos-de-la-

biodiversidad/cb vae evaluacion ecosistemas milenio.aspx

Ministerio de Agricultura, Pesca y Alimentación (MAPAMA) (2018) Estadística general de incendios forestales. https://www.mapama.gob.es/es/desarrollorural/estadisticas/Incendios_default.aspx.

NASA (2017a) MODIS. Moderate Resolution Imaging Spectroradiometer. https://modis.gsfc.nasa.gov/ 2018.

NASA (2017b) VIIRS. Visible Infrared Imaging Radiometer Suite (VIIRS). https://jointmission.gsfc.nasa.gov/viirs.html 2018.

Picos J (2018a) Comunicación personal sobre os incendios forestais en Pontevedra.

Picos J (2018b) Comunicación personal sobre os presos de producción das especies forestais. forest

Potschin, M. and Haines-Young, R. (2016): Defining and measuring ecosystem services. In: Potschin, M., Haines-Young, R., Fish, R. and Turner, R.K. (eds) Routledge Handbook of Ecosystem Services. Routledge, London and ä New York, pp 25-44.

Richardson, LA., Champ, PA., Loomis, JB. (2012) The hidden cost of wildfires: economic valuation of health effects of wildfire smoke exposure in Southern California. Journal of Forest Economics, 18: 14-35.

Sistema Europeo de Información sobre Incendios Forestais (SIEIF) European Forest Fire Information System (EFFIS) (2017). Dispoñible online en: http://effis.jrc.ec.europa.eu/about-effis/

The Economics of Ecosystem and Biodiversity (TEEB). Available at: http://www.teebweb.org/.

Valero E, Picos J, Herrera M (2007) Cálculo de las emisiones de CO2 por los incendios de 2006 en la provincia de Pontevedra (Galicia). In: Anonymous Comunicación presentada en el 4th International Wildland Fire Conference, Sevilla.

Xunta de Galicia (2018) Poxas.

http://mediorural.xunta.gal/areas/forestal/producion_e_industrias/poxas/. Accessed 20/07/20182018.

Revista Galega de Economía: http://www.usc.es/econo/RGE/benvidag.htm 